\title{
ORLANDO FURIOSO
}

\author{
DI \\ M. LODOVICO \\ ARIOSTO \\ ED \\ I CINQUE CANTI \\ DEL
}

MEDESIMO AUTORE

I QUALI SEGUONO LA MATERIA

DEL

F URIOSO.

EDIZIONE

Dt

GIUSEPPE DE' VALENTI.

BERLINO E STRALSUNDA

PRESSO AMADEO AUGUSTO LANGE MDCCLXXXYI. 



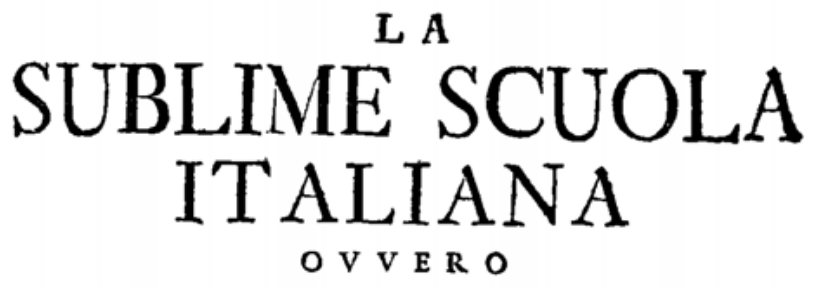

LE PIU ECCELLENTI OPERE

D I

PETRARCA, ARIOSTO, DANTE, T. TASSO,

PULCI, TASSONI, SANNAZZARO,

CHIABRERA, BURCHIELLO.

MACCHIAVELLI , BOCCACCIO , CASA, VARCHI, SPERONE SPERONI, LOLLIO,

GOZZI, MARTINELLI, ALGAROTTI.

"Cosi vidi adnnar la bella Scuola

"Del bel Paefe là, ove 'l Si fuona.

Dante Inf. C. 4 e C. 33 .

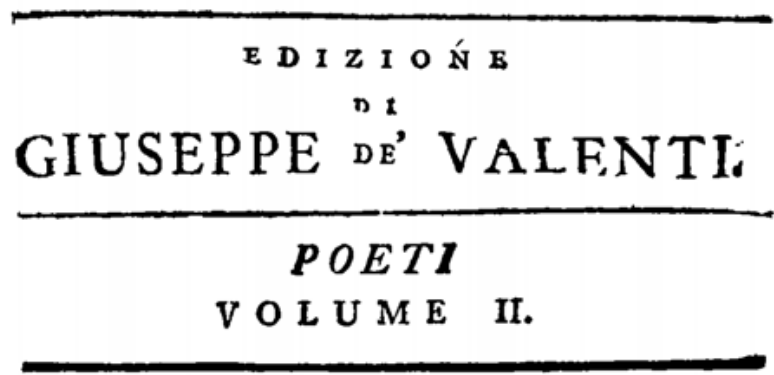

BERLINO E STRALSUNDA

RESSO AMADEO AUGUSTO LANGE $M D G C L X X X V I$. 
